\title{
The Impact of Undocumented Immigration on ID Theft in the United States: An Empirical Study
}

\author{
Richard J. Cebula, ${ }^{*}$ and James V. Koch ${ }^{2}$ \\ ${ }^{I}$ Shirley \& Philip Solomons Eminent Scholar, Armstrong Atlantic University, Savannah, GA, USA \\ ${ }^{2}$ Old Dominion University, Norfolk, VA 23529, USA
}

\begin{abstract}
According to the U.S. Federal Trade Commission, identity theft constituted the number one consumer complaint in the United States in 2006. Using state-level data for the 50 states for 2005, we find, among other things, that the rate of reported identity theft per 100,000 population is directly related to the unemployment rate, the percent of the population residing in urban areas, and the extent of undocumented immigration. Of these variables, the undocumented immigration variable is by far the most important in terms of both weight and statistical significance.

"But he that filches from me my good name/Robs me of that which not enriches him/And makes me poor indeed" (Iago in Shakespeare's Othello, Act 3, Scene 3).
\end{abstract}

\section{INTRODUCTION}

"Identity theft is a blight on America's privacy and security landscape," opined Federal Trade Commission Chairman Deborah Platt Majoras [1]. There is little question but that cyber crime has grown dramatically in recent years [2], and identity theft is its most frequent manifestation. The Center for Identity Management and Information Protection estimated in 2008 that the average cost of an identity theft case to its victims and law enforcement was $\$ 31,000$ [3] and the Identity Theft Resource Center reported that the first one-half of 2008 saw a 69 percent increase in data breaches and ID theft [4].

When criminals illegally assume the identity of another individual ("ID theft"), they usually do so for financial reasons. More often than not, they intend to: (i) steal the victim's financial assets; or, (ii) obtain goods and services under false pretenses, without paying; or (iii) use the victim's identity as a cover for other illegal activities.

Michael Chertoff, the U.S. Homeland Security Director, argues that undocumented immigrants are among the major ID theft offenders [5]. Chertoff believes undocumented immigrants largely engage in ID theft so they can obtain some else's social security number, thus enabling them to hold a job, open bank accounts, and the like. This is a testable hypothesis and we provide evidence on the issue in this paper.

Other hypotheses exist, however. Some theorize that ID theft is an Internet phenomenon, and there seems little doubt that some ID theft is accomplished by means of the Internet. The media, perhaps reflecting a desire to be politically correct, usually has focused upon this possibility. "Few Internet

*Address correspondence to this author at the Shirley \& Philip Solomons Eminent Scholar, Armstrong Atlantic University, Savannah, GA, USA;

E-mail: cebulari@mail.armstrong.edu security watchers believe 2007 will be any brighter for the millions of fraud-weary consumers already struggling to stay abreast of new computer security threats and avoiding clever scams when banking, shopping, or just surfing online," wrote a Washington Post reporter [6].

In this study, we examine differences in ID theft rates across the 50 states. We make interstate differences in ID theft rates a function of variables prompted by economic theory such as the economic conditions within each state and each state's law enforcement expenditures (which represent costs that might be imposed upon ID thieves). We also include oft-cited variables such as the urban $v s$ rural nature of the state, religious adherence, Internet access, education, and, of course, the incidence of undocumented immigrants in a state.

To presage our results, we find that the states with the highest ID theft rates tend to be those that have the highest percentages of undocumented immigrants. Internet access, on the other hand, is negatively related to the incidence of ID theft. This underscores the reality that while some of the most sophisticated instances of ID theft may involve the Internet, the massive majority of actual ID theft cases appears to involve simpler and more utilitarian motives---for example, undocumented immigrants stealing a social security number so that they can hold jobs in the U.S. and open bank accounts.

We find that the percentage of undocumented immigrants in a state is a highly significant predictor of the incidence of that state's ID theft. Furthermore, the state undocumented immigrant variable easily has the largest beta-coefficient in our predictive equation. Mr. Chertoff's surmises concerning ID theft and undocumented immigration may well be on target. Having said that, we immediately stress that much more work needs to be done on this subject. 


\section{THE INCIDENCE AND REPORTING OF IDENTITY THEFT}

The Identity Theft and Assumption and Deterrence Act [7] identifies an ID thief as someone who:

\begin{abstract}
...knowingly transfers or uses, without lawful authority, any name or number that may be used, alone or in conjunction with any other information, to identify a specific individual with intent to commit, or to aid and abet, any unlawful activity that constitutes a violation of Federal law, or that constitutes a felony under any applicable State or local law.
\end{abstract}

This definition of ID theft is rather broad, perhaps purposely so, because ID theft has been a rapidly evolving concept. The law seemingly was designed to deal with unforeseen circumstances brought about by technological change. Consequently, what one authority regards as ID theft, another may not, sometimes because the act in question is not regarded as significant, and other times because the act is so new that it hasn't yet found a spot on enforcers' proverbial radar screens.

The Federal Trade Commission (FTC) [8] reported that state ID theft rates in 2005 varied from a low of 24.8 per 100,000 persons in North Dakota to a high of 156.9 per 100,000 persons in Arizona. The median states, Hawaii and Alaska, had rates of 63.5 and 63.4, respectively. California, with a 125.0 rate, ranked third among the states, but had the largest total number of reported ID thefts $(45,175)$ in 2005. Table 1 summarizes these data. It is stressed that the year 2005 ID theft is considered because it is the most recent such state-level data set the FTC has provided to date.

Some ID thefts go unreported or even unrecognized. One reason for this is that several forms of ID theft are not regarded as criminal acts, or at least fail to be treated as such. To the sometime applause of the public, members of the media occasionally assume false identities in order to pursue a story and, providing they do not attempt to obtain personal financial benefit, this variety of ID theft is not considered illegal in many states. Or, if it is, it frequently goes unprosecuted. Law enforcement authorities themselves sometimes assume false identities in order to capture alleged law violators and federal court dockets not infrequently feature cases in which one of the issues is alleged law breaking or deception by law enforcement agencies.

In still other cases, "pretexting" (assuming a false identity in order to obtain information) is at the heart of the matter. In 2006, the information technology giant HewlettPackard engaged in pretexting in an attempt to obtain telephone records that might help identify a corporate leak. The Congress responded by approving a bill to criminalize pretexting aimed at obtaining someone's telephone records. Even so, many forms of pretexting do not violate federal, state, or local laws.

There are numerous forms of pretexting that seldom result in any legal action. Individuals often assume false identities on web sites such as www.myspace.com and www.facebook.com when they exaggerate their own virtues, or even blatantly lie about their essential characteristics (for example, a man telling a woman on myspace.com that he's 6'2" and a muscular 200 pounds rather than admitting that he's actually 5'4" and, 120 pounds). Such episodes may be frowned upon, but are seldom prosecuted unless they are accompanied by subsequent financial or sexual crimes.

The media frequently report large security breaches suffered by businesses and governmental agencies that apparently have exposed millions of individuals to potential ID theft. One episode elicited chuckles because the victim was Todd Davis, the CEO of LifeLock, a firm that strongly asserts in its advertising that it can keep thieves from stealing and utilizing your ID [9]. Another well-publicized example was the 2006 security breach at the U.S. Department of Veterans' Affairs, which resulted in lost personal data for an estimated 28.6 million veterans. Nor have the major credit card companies been exempt from security problems. In 2005, hackers penetrated the financial company Card Systems Solutions and stole personal data for more than 40 million Visa and MasterCard account holders. In the Veterans Affairs case, it appears this did not lead to significant ID theft, whereas in the credit card case, the effects have not been revealed.

This leads to a significant policy question. Should we regard these instances as ID theft because, in fact, individual identities were stolen, or focus instead only on those cases where the theft has recognizably led to criminal use of that ID? Actual Federal Trade Commission practice leans in the latter direction and therefore its published data might be viewed as minimizing the actual occurrence of ID theft. Nevertheless, the FTC received almost 250,000 ID theft complaints in 2006 [8].

The relevant point is the ID theft data published by the FTC report provide only a partial glimpse of ID theft and have obvious flaws [8]. An act one individual or law enforcement officer regards as an actionable instance of ID theft may not be interpreted similarly by another individual or policeman. Hence, that act may go unreported. The FTC [8] estimates that 61 percent of American ID theft victims do not notify a police department. Further, 32 percent of reported ID thefts were not discovered until a year after the theft occurred. By then, the metaphorical horse is gone from the barn.

Even so, the FTC data, which focus on credit card, phone and bank fraud as well as employment and government documents fraud in the U.S., now constitute the best information available. Perhaps more important, even if these data are only approximations of reality, they nonetheless are being used for purposes of resource allocation and public policy. Both the Department of Justice and the FTC pay attention to these data when they allocate law enforcement resources, and the media and elected officials usually treat these data as if they were handed down on tablets from Mount Sinai. Hence, it is important to know what these data tell us about the nature and sources of ID theft.

\section{PREVIOUS WORK}

Until very recently, the major source of information concerning empirical studies of the determinants of ID theft has 
Table 1. Identity Victims by State (per 100,000 population)

\begin{tabular}{|c|c|c|c|c|c|c|c|}
\hline Rank & State & Victims Per 100,000 People & Number of Victims & Rank & State & Victims Per 100,000 People & Number of Victims \\
\hline 1 & Arizona & 56.9 & 9,320 & 26 & Alaska & 63.4 & 421 \\
\hline 2 & Nevada & 130.2 & 3,144 & 27 & Louisiana & 62.6 & 2,811 \\
\hline 3 & California & 125.0 & 45,175 & 28 & Massachusetts & 62.5 & 3,999 \\
\hline 4 & Texas & 116.5 & 26,624 & 29 & Ohio & 62.4 & 7,155 \\
\hline 5 & Colorado & 97.2 & 4,535 & 30 & Minnesota & 58.7 & 3,015 \\
\hline 6 & Florida & 95.8 & 17,048 & 31 & Alabama & 58.7 & 2,675 \\
\hline 7 & Washington & 92.4 & 5,810 & 32 & Kansas & 58.5 & 1,606 \\
\hline 8 & New York & 90.3 & 17,387 & 33 & Arkansas & 58.2 & 1,617 \\
\hline 9 & Georgia & 87.3 & 7,918 & 34 & Rhode Island & 58.2 & 626 \\
\hline 10 & Illinois & 87.3 & 11,137 & 35 & Tennessee & 57.2 & 3,412 \\
\hline 11 & Maryland & 86.6 & 4,848 & 36 & So. Carolina & 56.8 & 2,416 \\
\hline 12 & New Mex. & 84.7 & 1,634 & 37 & Nebraska & 52.3 & 919 \\
\hline 13 & Oregon & 81.7 & 2,973 & 38 & Idaho & 52.1 & 745 \\
\hline 14 & New Jersey & 75.5 & 6,582 & 39 & Wisconsin & 50.3 & 2,782 \\
\hline 15 & Michigan & 70.5 & 7,139 & 40 & Mississippi & 49.9 & 1,458 \\
\hline 16 & Delaware & 69.1 & 583 & 41 & New Hampshire & 49.2 & 645 \\
\hline 17 & Virginia & 68.2 & 5,183 & 42 & Wyoming & 44.0 & 224 \\
\hline 18 & Oklahoma & 67.7 & 2,403 & 43 & Kentucky & 43.5 & 1,815 \\
\hline 19 & Missouri & 67.6 & 3,920 & 44 & Montana & 42.5 & 398 \\
\hline 20 & Utah & 67.5 & 1,668 & 45 & West Virginia & 37.3 & 677 \\
\hline 21 & No. Carolina & 67.1 & 5,830 & 46 & Maine & 37.2 & 491 \\
\hline 22 & Indiana & 67.0 & 4,201 & 47 & Iowa & 36.7 & 1,090 \\
\hline 23 & Connecticut & 65.9 & 2,313 & 48 & Vermont & 32.3 & 201 \\
\hline 24 & Pennsylvania & 63.6 & 7,908 & 49 & South Dakota & 30.0 & 233 \\
\hline 25 & Hawaii & 63.5 & 810 & 50 & North Dakota & 24.8 & 158 \\
\hline \multicolumn{8}{|c|}{ Median: $63.4 / 63.5$} \\
\hline
\end{tabular}

Source: Federal Trade Commission [8].

been Newman and McNally [10]. In their review of the ID theft literature for the U.S. Department of Justice, the duo commented tersely that, "...there are only a handful of studies that focus exclusively on identity theft, but they vary widely in quality and scope". In point of fact, analytical studies are scarce to de facto non-existent, whereas there have been many articles that either have discussed the increasing incidence of ID theft, or have focused on the technological tricks thieves use to steal someone's ID. Nearly all studies eventually talk about the precautions that individuals and households might take in order to reduce their exposure. Smith and Lias [11] and Smith [12] are representative of this approach. Their studies address the incidence of ID theft occurs, the usual ways in which it occurs, and what countermeasures individuals might take to reduce their vulnerability. Smith and Lias [13], for example, surveyed 75 managerial employees in the Pittsburgh area, whereas Smith [14] focused on a sample of 107 "working professionals" in the
Pittsburgh metropolitan area to ascertain how they have dealt with potential or real ID theft.

The Newman and McNally [10] survey contains only a handful of other references to research studies and these studies tend to rely heavily upon survey responses. Star Systems [13] polled approximately 3,000 individuals via telephone; Gartner Consulting [14] sampled 5,000 households; Harris Interactive [15] repeatedly has surveyed groups ranging in size from 2,000 to 5,000; and the Federal Trade Commission [16] conducted a randomized telephone survey of 4,057 individuals.

More recently, a survey by the Council of Better Business Bureaus and Javelin Strategy and Research [17] relied upon 5,000 telephone interviews and in contrast to most other studies, interestingly concluded that the growth of ID theft has been tapering off. Nevertheless, the study concluded that 8.9 million American adults had been victimized 
by ID theft in 2005 and that the average financial loss per occurrence had risen to $\$ 6,383$ [17].

The commonality among these studies is their reliance upon a descriptive approach to the ID theft phenomenon. Like ornithologists cataloging birds, the authors of these studies describe the major varieties of ID theft and then proceed to outline precautions individuals can take in order to minimize their potential exposure to ID thieves. Thus, we are advised to choose complicated, not easy to understand, passwords on the Internet and to avoid supplying our social security numbers unless absolutely necessary and then never in an e-mail. These studies are not analytical and do not rigorously probe the determinants of ID theft. Thus, we are left to wonder which populations are the most likely to commit ID theft, as well as whether unemployment plays a role in ID theft, whether ID theft is an urban phenomenon, and how the Internet might be involved in ID theft.

The only published formal empirical study to date to suggest (albeit in tentative terms) undocumented immigrants in the U.S. as major perpetrators of ID theft is that by Cebula, Koch, and Unemori [18]. In the absence of concrete analytical studies, the typical interpretation adopted by the media, but one not based upon formal empirical analysis, is that well-educated American computer hackers and high technology thieves based in locations such as the Ukraine and the People's Republic of China are the parties guilty of ID theft. It is possible that such malefactors are more significant in terms of the financial impact of their transgressions, but they are not so in terms of the absolute number of offenses.

We wish to emphasize that our results do not preclude such "foreign" parties from possible blame. However, in the case of foreign-based ID thieves, they are not directly included in our analysis since we examine the 50 U.S. states. We do not discount the fact that an American using the Internet to make a purchase can be duped by an Internet site that takes his money but does not deliver him the goods. Indeed, this happened to one of the authors during the 2007 Christmas season. Our point is that the incidence of such cases may be dwarfed by immigrant-related ID theft.

\section{A SIMPLE MODEL}

Whereas some data are available that quantify ID theft for metropolitan areas, the best political unit data available relate to the 50 states. Accordingly, our goal is to explain variations in the rate of ID theft using state-level data. Hence, we estimate a reduced-form equation of the following form:

$\mathbf{R}_{i}=a+b \mathbf{X}_{i},+u_{i}$

where:

$\mathbf{R}_{i}=$ rate of reported ID theft per 100,000 individuals during the year 2005 in state " $i$ "

$\boldsymbol{a}=$ estimated constant

$\boldsymbol{b}=$ estimated regression coefficients
$\mathbf{X}_{i}=$ vector of state characteristics such as population demographics, economic status, apparent religious commitment, urban versus rural residence, education, Internet access

$\boldsymbol{u}_{\boldsymbol{i}}=$ stochastic error term.

We adopt seven categories of explanatory variables for each state:

- $\quad$ Economic conditions (UNEMPL, each state's unemployment rate in 2004) [19]

- Urban/rural nature (URBAN, the percent of each state's population living in an urban area in 2000) [20]

- Law enforcement expenditures (LAWENEXP, law enforcement expenditures per capita in each state, 2004) [21]

- Extent of religious affiliation (RELIGION, the percent of each state's population that identified itself as being either Christian or Jewish, 2000) [22]

- Internet access (INTERNET, the percent of households in each state connected to the Internet, 2003) [23]

- Incidence of undocumented immigrants (UNDOCIMM, the estimated percent of each state's population consisting of undocumented immigrants, as of March, 2005) [24]

- $\quad$ The percent of each state's population, age 25 years or older that has earned a bachelor's degree or higher, 2005 (EDUC) [25]

All of these variables represent the latest consistent, dependable versions of these data available at the state level. For example, as already observed above, 2005 is the most recent year for which dependable state-level ID theft data exist. In addition, especially noteworthy is the fact that the U.S. Census does not as yet have dependable state-level data for the variables URBAN and RELIGION that are more recent than the year 2000 .

\section{EMPIRICAL RESULTS}

OLS estimates, with White [26] heteroskedasticitycorrected standard errors, of three alternative versions of the basic model are found in Table 2 . Regression 1 reports the results based upon the model with EDUC excluded. Except for the sign of the Internet access variable, the signs of the coefficients of the independent variables in Regression 1 correspond with reasonable a priori expectations. The sign on the coefficient of the undocumented immigrants variable is highly significant (at the one percent level) and boasts a large $\beta$-coefficient that is more than three times the size of any other explanatory variable. This is hardly surprising, since only a cursory examination of Table $\mathbf{1}$ is necessary to see that the states with the largest incidence of ID theft also have the largest incidence of undocumented immigrants (see Arizona and California as good examples). Here, however, we have documented that relationship in a ceteris paribus context in which other relevant factors such as economic 
conditions, the extent of the states' urban population, law enforcement expenditures, religious adherence, and Internet access have been held constant in the estimating equation.

Table 2. Determinants of ID Theft: OLS Results for the Year 2005

\begin{tabular}{|c|c|c|c|}
\hline \multirow{2}{*}{$\begin{array}{l}\text { Explanatory } \\
\text { Variables }\end{array}$} & \multicolumn{3}{|c|}{$\begin{array}{l}\text { Regression Coefficients, Standard Errors, } \\
\text { and } \beta \text {-Coefficients }\end{array}$} \\
\hline & Regression 1 & Regression 2 & Regression 3 \\
\hline UNEMPL & $\begin{array}{c}5.448 \\
(1.41)^{* * *} \\
\beta=.21\end{array}$ & $\begin{array}{c}5.685 \\
(1.45)^{* * *} \\
\beta=.22\end{array}$ & $\begin{array}{c}6.104 \\
(1.19)^{* * *} \\
\beta=.23\end{array}$ \\
\hline URBAN & $\begin{array}{c}0.387 \\
(0.132)^{* * *} \\
\beta=.22\end{array}$ & $\begin{array}{c}0.363 \\
(0.135)^{* * *} \\
\beta=.21\end{array}$ & $\begin{array}{c}0.486 \\
(0.12)^{* * *} \\
\beta=.27\end{array}$ \\
\hline LAWENEXP & $\begin{array}{c}0.001 \\
(0.001) \\
\beta=.085\end{array}$ & $\begin{array}{c}0.001 \\
(0.001) \\
\beta=.078\end{array}$ & ------ \\
\hline RELIGION & $\begin{array}{c}-0.317 \\
(0.135)^{* *} \\
\beta=.13\end{array}$ & $\begin{array}{c}-0.338 \\
(0.138)^{* *} \\
\beta=.14\end{array}$ & $\begin{array}{c}-0.386 \\
(0.102)^{* * *} \\
\beta=.16\end{array}$ \\
\hline INTERNET & $\begin{array}{c}-0.395 \\
(0.243)^{*} \\
\beta=.092\end{array}$ & $\begin{array}{c}-0.651 \\
(0.315)^{* *} \\
\beta=.13\end{array}$ & $\begin{array}{c}-0.754 \\
(0.219)^{* * *} \\
\beta=.19\end{array}$ \\
\hline UNDOCIMM & $\begin{array}{c}8.546 \\
(0.911)^{* * *} \\
\beta=.69\end{array}$ & $\begin{array}{c}8.549 \\
(0.915)^{* * *} \\
\beta=.69\end{array}$ & $\begin{array}{c}8.789 \\
(1.20)^{* * *} \\
\beta=.74\end{array}$ \\
\hline EDUC & ------ & $\begin{array}{c}0.349 \\
(0.419) \\
\beta=.063\end{array}$ & ------- \\
\hline CONSTANT & $\begin{array}{c}20.46 \\
(18.33)\end{array}$ & $\begin{array}{l}21.87 \\
(18.47)\end{array}$ & $\begin{array}{c}27.37 \\
(15.76)^{*}\end{array}$ \\
\hline$R^{2}$ (adj.) & 0.884 & 0.884 & 0.881 \\
\hline $\mathrm{F}$ & $63.49 * * *$ & $54.13 * * *$ & $73.18 * * *$ \\
\hline
\end{tabular}

***Probability $=0.01 ; * *$ Probability $=0.05 ; *$ Probability $=0.10$.

Notes: All regressions adopt the White [21] heteroskedasticity adjustment. The $\beta$ coefficients are expressed as absolute values. The significance tests are two-tailed.

We cannot ascertain from the regressions in Table 2 whether the ID thefts perpetrated in states that have proportionately large numbers of undocumented immigrants are more or less serious in terms of their aggregate financial impact. It is reasonable to conclude, however, that the presence of undocumented immigrants in a state dramatically increases the incidence of ID theft in that state. Specifically, a one percent increase in undocumented aliens in a state generates an 8.546 unit increase in that state's rate of ID theft per 100,000 residents. This translates to a 13.01 percent increase in a representative state's ID theft rate. Thus, the ID theft response of a state to an increased proportion of undocumented aliens is highly elastic. That is, a representative state's ID theft rate responds very robustly to an increase in the proportion of undocumented immigrants in that state.

We also observe that state unemployment rates generate higher state rates of ID theft. This relationship, which cannot be regarded as surprising (the higher the unemployment rate, the greater the incentive to seek income from non- employment forms, including ID theft), is statistically significant at the one percent level. Similarly, our finding that highly concentrated urban populations in a state are conducive to ID theft corresponds with intuition. This estimated coefficient is statistically significant at the one percent level. It seems reasonable to assume that it is more difficult and perhaps less rewarding to commit ID theft in a rural situation since fewer people are accessible vis-à-vis a more urban setting. Moreover, "dumpster diving" is less likely to be a viable source of ID theft in rural areas than in urban areas.

Law enforcement is potential deterrent to ID theft. Increased law enforcement, at least if it is focused upon ID theft, imposes additional costs on ID thieves. Hence, ceteris paribus, states that expend more resources on law enforcement per capita may deter some ID thieves and be better situated to deal with ID theft. Our results do not support this notion; indeed, the coefficient of this variable fails to be statistically significant at even the ten percent level. One reason for this flaccid relationship may be that generalized law enforcement expenditures not focused upon ID theft may well have only minimal (if any) direct effects upon the incidence of ID theft. Murder investigations and ID theft investigations are not the same thing.

It seems plausible to assume that those individuals who have strong religious beliefs and connections may be less likely to commit ID theft. Our proxy for these "moral" constraints is the percent of a state's adult population that declares itself to be either Christian (including Mormons), or Jewish. We find that states with high religious adherence have lower rates of ID theft, holding other things constant. This relationship is statistically significant at the five percent level.

It is the negative sign on the Internet access coefficient that some might find confounding. Ceteris paribus, the negative coefficient suggests (albeit modestly in Regression 1) that increased Internet access diminishes ID theft. This finding conflicts with the view of some who regard ID theft as a fundamentally Internet-based phenomenon. The latter view appears to be false, at least as it applies to the incidence of ID theft, although it could still be true that Internet-based ID thefts involve the greatest dollar sums. These observations notwithstanding, since the coefficient on this variable is statistically significant at barely the ten percent level, it might useful to consider the results for this variable in the other estimates, where both its statistical significance and $\beta$ coefficients are greater.

State variations in the ID theft rate are much more sensitive to factors other than Internet access, especially the presence of undocumented aliens in a state. Indeed, if we hold economic conditions, urbanity, religion and other factors constant, then Internet access may well be a proxy for the relative sophistication of a state's residents in the use and protection of sensitive, private information. That is, if we and others in my state had Internet access in our homes in 2003 , then we might have been less likely to place ourselves in situations where our social security numbers or driver's licenses could be stolen. We also might have been more likely to erect Internet defenses against scams, "phishing," 
spy bots, and other techniques that might induce us to supply such information, willingly or unwillingly.

Regression 2 is quite similar to Regression 1, except that the education variable EDUC (the percent of each state's population age 25 or higher that has earned a bachelor's degree or higher) has been included as an argument. It adds no explanatory power, is not statistically significant, and has a very low $\beta$-coefficient. This finding seemingly supports the view that most ID theft is a not an upper income, high education activity. Instead, ID theft appears to be much more strongly related to the presence of unemployment in a state, the urban/rural nature of a state, and the presence of undocumented immigrants in that state.

We note once again that it could still be true that the most costly financial episodes of ID theft involve highly educated, upper income individuals. Nevertheless, the great mass of ID theft cases appears to be more tightly connected to phenomena not usually associated with high incomes and high levels of education. Finally, in Regression 2, the coefficient on the INTERNET variable remains negative and is significant at the five percent level.

As a test of robustness of the basic model and in the search for clearer results, Regression 3 in Table 2 excludes the two statistically insignificant variables found in Regressions 1 and 2, namely, LAWENEXP and EDUC. Given the presence of a modest degree of multicollinearity between these two variables and other explanatory variables in the analysis, the robustness of the results shown in Regression 3 is not surprising. In this specification, all five of the estimated coefficients exhibit the corresponding signs as described in Regressions 1 and 2; furthermore, all five of the estimated coefficients are statistically significant at the one percent level. Finally, the $\beta$-coefficients are higher for all five of the variables in this estimate than in either Regression 1 or Regression 2 . This lends credibility and strength to the statistically significant inferences derived in Regressions 1 and 2. In particular, the ID theft rate is a decreasing function of RELIGION and INTERNET and an increasing function of UNEMPL, URBAN, and UNDOCIMM. Once again, the last of these, UNDOCIMM, has by far the highest statistical significance and by far the highest $\beta$-coefficient.

\section{CONCLUSIONS}

This study clearly is exploratory in character. The results are intriguing, but we would be wise to note the caveats dispensed by Friedman and Schwartz [27] and Tomek [28], who have warned of the perils associated with strong policy conclusions based upon the statistical significance of coefficients in single regression equations. These economists stress that much more heed should be accorded repetitive results that have been confirmed under appropriately rigorous testing circumstances. Results that emanate from a single study, however strong, must be regarded as preliminary.

We state the obvious when we point out that that statelevel ID theft data necessarily yield limited conclusions. We need to perform more work at the level of metropolitan areas, cities, and individuals in order to reach stronger conclu- sions. Furthermore, there is the danger of falling prey to the ecological fallacy, that is, to inferring individual conclusions from group data. Here, this means that we can make statements about state-level data and variables, but not directly about individuals. We cannot unequivocally conclude that undocumented immigrants are a major cause of ID theft; however, we can state that a clear pattern exists in which those states that have relatively more undocumented immigrants do have much higher rates of ID theft.

If the number of victims and the adverse financial impact of ID theft are as large as major media suggest [29], then we ought to be interested in the sources of this fraud and, more specifically, who is committing these frauds. Policy-makers need concrete information upon which they can act and the results reported here move them in this direction. We have taken a first step in providing such information.

Michael Chertoff, the nation's Director of Homeland Security, surmised that undocumented immigrants have been heavily involved in ID theft [5]. Our results indicate that his speculations are well worth additional investigation. Perhaps a significant proportion of ID theft could be eliminated if attention were paid to ways and means by which undocumented immigrants illegally both acquire and then utilize personnel ID information belonging to legal residents of the United States.

\section{REFERENCES}

[1] Federal Trade Commission. The President's Identity Theft Task Force Releases Comprehensive Strategic Plan to Combat Identity Theft. http://www.ftc.gov/opa/2007/04/idtheft.shtm.

[2] Swarns RL. Illegal Immigrants at Center of New ID Theft Crackdown. New York Times, 2006; 156: A26.

[3] Burger AK. The Cost of ID Theft, Part I: Beyond Dollars and Cents, E-Commerce Times, 2008 February 5. http://www.ccommercetimes.com/story/61515.html?welcome=1202389102.

[4] Krebs B. Data Breaches are Up 69\% This Year, Nonprofit Says. Washington Post, 2008, July 1, http://www.washingtonpost.com/ wp-dyn/content/article/2008/06/30/AR2008063002123.html.

[5] Leinwand D. Immigration Raid Linked to ID Theft, Chertoff Says. USA Today, 2006, December 13, http://www.usatoday.com/ news/nation/2006-12-13-immigration_x.htm.

[6] Krebs B. Cyber Crime Hits the Big Time in 2006. Wash Post Online. 2006, December 22, http://www.washingtonpost.com/wpdyn/content/article/2006/12/22.

[7] The Identity Theft and Assumption and Deterrence Act, Title 18 , USC 1028 .

[8] Federal Trade Commission. Identity Theft Victim Complaint Data: Figures and Trends, Federal Trade Commission. Washington, DC, 2006.

[9] PC World. ID Protection Firm LifeLock Sued by Customers When CEO's ID Is Stolen. PC World, 2008, http://blogs.pcworld. com/staffblog/archives/007008.html.

[10] Newman GR, McNally MM. Identity Theft Literature Review. Report to the National Institute of Justice, Office of Justice Programs, U.S. Department of Justice, Contract \#2005-TO-008.

[11] Smith AD, Lias AR. Identity Theft and E-Fraud as Critical CRM Concerns. Intern J Ent Info Sys 2005; 1: 17-36.

[12] Smith AD. Identity Theft as a Threat to CRM and E-Commerce. Elec Govt: Intern 2005; 2(2): 219-46.

[13] Star Systems. Identity Theft and Security Concerns: 2002 Consumer Survey.2002, www.star.com/pdf/STARIDTheft.pdf,

[14] Gartner Consulting. 2007, http://news.zdnet.com/2100-1009_226164765.html.

[15] Harris Interactive. 2002, http://www.harrisinteractive.com/.

[16] Federal Trade Commission. 2007, April. http://www.consumersunion.org/campaigns/financialprivacynow/2007/04/fact_sheet_about_id theft_1.htm. 
[17] Johannes R. The 2006 Identity Fraud Survey. Council of Better Business Bureaus and Javelin Strategy and Research, Pleasanton, CA, 2006

[18] Cebula R, Koch J, Unemori M. An Empirical Analysis of Identity Theft Determinants in the U.S., Rev Bus Res, 2007; 7 (6): 1-8.

[19] U.S, Census Bureau, Stat Abst U.S., Washington, DC: U.S Government Printing Office, 2006, Table 581.

[20] U.S. Census Bureau, Stat Abst U.S.: Washington DC: U.S. Government Printing Office, 2006, Table 27.

[21] U.S. Census Bureau, Stat Abst U.S.: Washington, DC: U.S. Government Printing Office, 2006, Table 431.

[22] U.S. Census Bureau, Stat Abst U.S.: Washington, DC: U.S. Government Printing Office, 2006, Table 71.

[23] U.S. Census Bureau, Stat Abst U.S.: Washington, DC: U.S. Government Printing Office, 2006, Table 1150.
[24] Pew Hispanic Center. Estimates of the Unauthorized Migrant Population for States Based on the March 2005 CPS, http://www.pewhispanic.org.

[25] U.S. Census Bureau, Stat Abst U.S. Washington, DC: U.S. Government Printing Office, 2006, Table 218.

[26] White H. A Heteroskedasticity-Consistent Covariance Matrix Estimator and a Direct Test for Heteroskedasticity. Econometrica, 48; 1980: 817-38.

[27] Friedman M, Schwartz A J. Alternative Approaches to Analyzing Economic Data, Amer Econ Rev, 81; 1991: 39-49.

[28] Tomek W.G. Confirmation and Replication in Empirical Econometrics: A Step toward Improved Scholarship. Amer J Ag Econ, 75; 1993: 6-14.

[29] New York Times. http://topics.nytimes.com/top/reference/ timestopics/subjects/i/identity_fraud/index.html?scp=1spot\&sq=id+theft\& st=nyt, 2008, June 30 .

(C) Cebula and Koch; Licensee Bentham Open.

This is an open access article distributed under the terms of the Creative Commons Attribution License (http://creativecommons.org/licenses/by/2.5/), which permits unrestrictive use, distribution, and reproduction in any medium, provided the original work is properly cited. 